\title{
Clinical Effects of a Plant Extract Mixture Containing Rhus verniciflua and Other Herbs in Tumor Bearing Dogs
}

\author{
Francisco Clemente-Vicario1, C. Guillermo Couto', Kohei Suruga², Yasuhiro Komatsu',4, \\ C. A. Tony Buffington ${ }^{1}$, William C. Kisseberth ${ }^{1}$ \\ ${ }^{1}$ Department of Veterinary Clinical Sciences, The Ohio State University College of Veterinary Medicine, \\ Columbus, $\mathrm{OH}$, USA \\ ${ }^{2}$ International Operation Department (FM Center for R \& D), Kibun Foods Inc., Tokyo, Japan \\ ${ }^{3}$ Kitasato Institution for Life Science, Kitasato University, Tokyo, Japan \\ ${ }^{4}$ Sun R \& D Institute for Natural Medicines Co. Inc., Tokyo, Japan \\ Email: *kisseberth.2@osu.edu
}

Received 1 April 2016; accepted 25 June 2016; published 28 June 2016

Copyright (C) 2016 by authors and Scientific Research Publishing Inc. This work is licensed under the Creative Commons Attribution International License (CC BY). http://creativecommons.org/licenses/by/4.0/

\section{(c) (i) Open Access}

\section{Abstract}

Dog owners are increasingly seeking treatment when their pets develop cancers. As in human cancer patients, dogs with cancer are commonly treated with complementary and alternative therapies, including herbal medicines and nutritional supplements. A novel antitumor agent was developed from six different herbs including Rhus verniciflua (Rv-PEM01). The components were established from traditional herbal medicine and designed to affect antitumor activity and maintain host immune function. Previous studies identified anti-proliferative activity in human, murine and canine cancer cell lines. In this clinical study the safety and tolerability of Rv-PEM01 were evaluated in pet dogs with spontaneously occurring cancers. Twelve dogs were treated orally daily for 30 days in escalating dose ( $4-10 \mathrm{mg} / \mathrm{kg}$ orally once daily) cohorts. Rv-PEM01 was well tolerated; only transient mild elevations in BUN were observed in 2 dogs. Although tumor response was not a primary endpoint for this study, stable disease was maintained for 30 days in 5 (42\%) of the dogs. In conclusion, Rv-PEM01 was found to be safe and well tolerated in the dosage range tested. Future studies should evaluate higher dosages of Rv-PEM01 in dogs with cancer, and specifically address other potential benefits of Rv-PEM01 in canine cancer patients, including correlative assessments of immune function, quality of life and owner satisfaction.

\footnotetext{
${ }^{*}$ Corresponding author.
} 


\section{Keywords}

\section{Rhus verniciflua, Dog, Cancer, Complementary and Alternative Medicine}

\section{Introduction}

Companion dogs are an important part of many people's lives, and many pet owners consider their dogs to be family members [1]. As members of their family, dog owners are seeking better health care for their pets. This includes the use of complementary and alternative medicine (CAM) for themselves and for their pets. In one large study, $75 \%$ of people reported using CAM at some time in their lives [2]. Furthermore, CAM is used by the majority of human patients with cancer [3]. For example, some type of herbal or vitamin supplement was used by almost half of patients with breast cancer [4], and between $20 \%$ and $55 \%$ of human cancer patients report using herbal and dietary supplements [5]. The goals of CAM therapies vary, but in general they are used to alleviate physical and emotional symptoms, improve quality of life, and possibly to improve adherence to oncology treatment regimens [6]. Not surprisingly, as companion dogs are an important part of many people's lives, the demand for CAM for dogs with cancer is also growing. In one survey, $76 \%$ of owners of dogs and cats with cancer reported using CAM in treating their pet, with nutritional supplements being the most commonly used therapy [7]. Clearly, the demand for such forms of therapy is present.

The popularity of CAM is an international trend in cancer therapy. Due to the often severe side effects and limited therapeutic efficacy of many chemotherapeutic agents used in conventional cancer treatment, CAM might be able to improve clinical outcomes and reduce toxicities associated with administration of some anticancer drugs. Several Kampo (traditional Japanese herbal medicine) medicines, such as Keishi-ka-kei-to, Juzentaiho-to, Shimotsu-to, Unsei-in, Hochu-ekki-to, Shosaiko-to and Shichimotsu-koka-to have been reported to exhibit an antimetastatic effect, and among them, Keishi-ka-kei-to, Juzen-taiho-to, Shosaiko-to and Shichimotsukoka-to also exert antiproliferative activity on cancer cell lines [8]. A report of the beneficial effects of an herbal compound containing bloodroot (Sanguinaria canadensis) extract on two dogs that were referred for surgical removal of cutaneous tumors recently was published. Herbal and botanical products containing bloodroot extract are commonly used for a treatment in veterinary oncology, but some authors report that the bloodroot and other escharotics constitute potentially very harmful herbal substances and their use should be limited to in-patient use and/or neoplastic dermatological lesions [9].

We have been analyzing the antitumor activity of plant extracts containing Rhus verniciflua, as well as their ability to maintain host immune capacity. $R$. verniciflua is commonly known as the lacquer tree, and urushiols, the major compounds of lacquer tree sap, have antioxidant and cytotoxic effects [10]. In our previous reports, we showed the anti-proliferative activities of a plant extract mixture from six kinds of herbs including $R$. verniciflua (Rv-PEM01) in vitro. Rv-PEM01 had an inhibitory effect on the proliferation of human, mouse and canine tumor cell lines [11] [12]. Based on these encouraging in vitro results, we conducted a clinical study of Rv-PEM01 in dogs with spontaneously occurring cancers to determine the safety and tolerability of Rv-PEM01 in this population and to document evidence of antitumor activity.

\section{Materials and Methods}

\subsection{Eligibility}

A clinical trial was performed at The Ohio State University Veterinary Medical Center (OSUVMC) in clientowned dogs with spontaneously occurring solid tumors. The trial was approved by the OSUVMC Clinical Research Committee (CRC) and the OSU Institutional Animal Care and Use Committee (IACUC). Written informed consent was obtained prior to patient enrollment. Eligible dogs were required to have a histologic or cytologic diagnosis of solid tumor (carcinoma, sarcoma, melanoma, mast cell tumor). Dogs that had failed standard therapy, or for which no effective standard therapeutic option was available, or conventional therapies were declined, were enrolled. Dogs had to meet all eligibility criteria, including: at least 1 year of age; a modified Eastern Cooperative Oncology Group (ECOG) performance status of 0 - 1; adequate organ function as determined by routine blood work; at least 2 weeks from previous anti-neoplastic treatments (chemotherapy, radia- 
tion therapy, surgery, other investigational therapies) and complete resolution of clinical toxicities from these treatments. Dogs with lymphoma and leukemia were excluded. Prior to enrollment, dogs underwent screening tests including medical history, physical examination, complete blood count, serum biochemical profile, urinalysis, and imaging (thoracic radiographs, abdominal ultrasound) if needed for tumor measurements.

\subsection{Rv-PEM01 Formulation}

Rv-PEM01 (Sun R \& D Institute for Natural Medicines Co., Inc., Tokyo, Japan), a mixture of plant extracts includes Rhus verniciflua, Ulmus hollandica, Polygonatum sibiricum, Lycium chinense, Ganoderma japonicum, and Panax ginseng, was formulated as $20 \mathrm{mg}$ tablets and provided by Kibun Foods, Inc. (Tokyo, Japan). RvPEM01 was administered by mouth once daily.

\subsection{Study Design}

This study was a single center open-label, nonrandomized, sequential group, dose escalation study of RvPEM01 in client owned dogs with spontaneous solid tumors. Dogs were evaluated at day 0, day 7 and day 30. A complete blood count and serum biochemistry profile was evaluated at each visit. Dogs were enrolled in cohorts of three patients; the first cohort was treated at a starting dose of $4 \mathrm{mg} / \mathrm{kg}$ orally once daily and subsequent cohorts were treated at increasing dose levels $(6,8$, and $10 \mathrm{mg} / \mathrm{kg} /$ day). If none of the three patients in a cohort experienced a dose-limiting toxicity (DLT), another three patients was treated at the next higher dose level. However, if one of the first three patients experiences a DLT, three more patients would be treated at the same dose level. The dose escalation would continue until at least two patients in a cohort of three experienced DLT. The DLT was considered any grade 3 or 4 toxicity based on the VCOG-CTCAE v1.1 criteria [13]. Disease progression or adverse events (AEs) related to disease were not considered adverse events. If stable disease, partial response, or complete response was achieved at day 30, Rv-PEM01 could be continued, if desired by the owner, off-study, until progressive disease was observed.

\subsection{Toxicity Assessment}

Assessments for adverse events were performed on days 7 and 30. Dogs experiencing severe adverse events (SAE) were not permitted to continue Rv-PEM01 therapy. A SAE was defined as any grade 4 or 5 toxicity as defined by the VCOG-CTCAE v1.1 criteria [13].

\subsection{Tumor Response Assessment}

Tumor response assessments were performed on days 7 and 30. Dogs were permitted to continue to receive Rv-PEM01 beyond day 30 provided they had not experienced unacceptable toxicity and had no evidence of disease progression. Tumor response assessments were performed by caliper measurement of accessible tumors. Thoracic or abdominal masses were assessed using thoracic radiographs or ultrasonography, respectively. Responses were assessed using the Response Evaluation Criteria for Solid Tumors in Dogs (v1.0) [14]. A complete response (CR) was defined as disappearance of all disease on two measurements separated by a minimum period of 2 weeks. A partial response (PR) was defined as greater than 30\% reduction in the sum of the longest diameter of the target lesions documented by two assessments separated by at least 2 weeks. Progressive disease (PD) was defined as an increase of $>20 \%$ in the sum of the longest diameters of the target lesions, using the smallest sum since initiation of therapy as a reference, or the appearance of any new lesion(s). Stable disease (SD) was defined as the absence of criteria for either a response or progression.

\section{Results}

\subsection{Study Population}

Twelve dogs with spontaneously occurring solid tumors were enrolled in the clinical trial. Patient demographics are summarized in Table 1. A total of 9 purebred and 3 mixed breed dogs were enrolled. The median age was 10.1 years and the median weight was $31.2 \mathrm{~kg}$. Five dogs had received prior chemotherapy for their tumors; the remaining 7 dogs were treatment naïve. The tumor histologies treated included soft tissue sarcoma (4), hemangiosarcoma (4), osteosarcoma (2), histiocytic sarcoma (1), and hepatocellular carcinoma (1). 
Table 1. Patient demographics.

\begin{tabular}{|c|c|c|c|c|c|c|c|c|}
\hline No. & Tumor & Dog & Sex & Age & $\begin{array}{l}\text { Weight } \\
(\mathrm{kg})\end{array}$ & Prior Therapy & $\begin{array}{l}\text { Rv-PEM01 dose } \\
\text { (mg/kg/day) }\end{array}$ & $\begin{array}{l}\text { Antitumor } \\
\text { Response }\end{array}$ \\
\hline 1 & $\begin{array}{l}\text { osteosarcoma } \\
\text { (metastatic) }\end{array}$ & Greyhound & FS & $7 \mathrm{y}, 7 \mathrm{~m}$ & 28.6 & $\begin{array}{l}\text { chemotherapy } \\
\text { surgery }\end{array}$ & 4 & PD \\
\hline 2 & $\begin{array}{l}\text { soft tissue sarcoma } \\
\quad \text { (grade 2) }\end{array}$ & Mixed Breed & $\mathrm{MC}$ & $14,5 \mathrm{~m}$ & 35.0 & none & 4 & $\mathrm{PD}$ \\
\hline 3 & $\begin{array}{l}\text { osteosarcoma } \\
\text { (primary) }\end{array}$ & Mixed Breed & $\mathrm{F}$ & $11 \mathrm{y}$ & 31.4 & chemotherapy & 4 & PD \\
\hline 4 & $\begin{array}{l}\text { hemangiosarcoma } \\
\text { (subcutaneous) }\end{array}$ & $\begin{array}{l}\text { German } \\
\text { Shepherd }\end{array}$ & FS & $10 \mathrm{y}, 3 \mathrm{~m}$ & 41.6 & none & 6 & PD \\
\hline 5 & $\begin{array}{l}\text { hemangiosarcoma } \\
\text { (subcutaneous) }\end{array}$ & $\begin{array}{l}\text { Golden } \\
\text { Retriever }\end{array}$ & $\mathrm{MC}$ & $10 \mathrm{y}, 2 \mathrm{~m}$ & 37.8 & none & 6 & SD \\
\hline 6 & $\begin{array}{l}\text { histiocytic sarcoma } \\
\text { (pulmonary) }\end{array}$ & $\begin{array}{l}\text { Flat-Coated } \\
\text { Retriever }\end{array}$ & FS & $8 \mathrm{y}, 11 \mathrm{~m}$ & 30.0 & surgery & 6 & SD \\
\hline 7 & $\begin{array}{l}\text { soft tissue sarcoma } \\
\text { (primary/metastatic) }\end{array}$ & $\begin{array}{l}\text { Golden } \\
\text { Retriever }\end{array}$ & FS & $9 \mathrm{y}, 1 \mathrm{~m}$ & 35.2 & $\begin{array}{l}\text { surgery radiation } \\
\text { chemotherapy }\end{array}$ & 8 & PD \\
\hline 8 & $\begin{array}{l}\text { hemangiosarcoma } \\
\text { (primary/metastatic) }\end{array}$ & $\begin{array}{l}\text { German } \\
\text { Shepherd }\end{array}$ & FS & $12 \mathrm{y}, 7 \mathrm{~m}$ & 39.2 & $\begin{array}{c}\text { surgery } \\
\text { chemotherapy }\end{array}$ & 8 & PD \\
\hline 9 & $\begin{array}{l}\text { soft tissue sarcoma } \\
\quad \text { (grade 1) }\end{array}$ & $\begin{array}{c}\text { Jack } \\
\text { Russell Terrier }\end{array}$ & $\mathrm{F}$ & $8 \mathrm{y}, 1 \mathrm{~m}$ & 10.0 & none & 10 & SD \\
\hline 10 & $\begin{array}{l}\text { soft tissue sarcoma } \\
\text { (grade 2) }\end{array}$ & $\begin{array}{l}\text { Labrador } \\
\text { Retriever }\end{array}$ & $\mathrm{MC}$ & $12 \mathrm{y}, 9 \mathrm{~m}$ & 32.6 & surgery & 8 & PD \\
\hline 11 & $\begin{array}{l}\text { hepatocellular carcinoma } \\
\text { (well-differentiated) }\end{array}$ & Mixed Breed & FS & $12 \mathrm{y}, 10 \mathrm{~m}$ & 25.8 & surgery & 10 & SD \\
\hline 12 & $\begin{array}{l}\text { hemangiosarcoma } \\
\text { (pelvic) }\end{array}$ & Bassett Hound & M & $3 \mathrm{y}, 6 \mathrm{~m}$ & 27.8 & chemotherapy & 10 & SD \\
\hline
\end{tabular}

F: female; FS: female spayed; M: male; MC: male castrate; PD: progressive disease; SD: stable disease.

\subsection{Clinical Toxicities and Maximum Tolerated Dose}

Adverse events were attributed to Rv-PEM01 as possibly, probably, definitely, unlikely, or unrelated. Those adverse events that were unlikely or unrelated to Rv-PEM01 administration were attributed to pre-existing conditions, tumor progression, other underlying conditions, minor deviations from normal (for CBC and serum biochemistries), or unknown. Only two adverse events could be (possibly) attributed to Rv-PEM01. These were grade 1 transient elevations in blood urea nitrogen (BUN) in two dogs. It is important to note that the serum creatinine was normal at the time of these elevations in both dogs and that the one dog for which a sample was available, the urine was concentrated, suggesting that the BUN elevations were due to non-renal causes. A maximum tolerated dose was not reached over the range of dosages $(4-10 \mathrm{mg} / \mathrm{kg} / \mathrm{day})$ evaluated. Owners did not report any particular difficulty administering the drug, i.e. in general it could be easily given in food.

\subsection{Response to Therapy}

Over the 30 day period of drug treatment 7 dogs developed progressive disease and 5 dogs had stable disease (Figure 1 and Table 1). One dog with stable disease, a well-differentiated hepatocellular carcinoma, continued therapy for another 10 months until euthanized for progressive disease. Rv-PEM01 was well-tolerated by this dog throughout the course of treatment.

\section{Discussion}

In this study Rv-PEM01 was found to be safe and well tolerated in pet dogs with spontaneously occurring solid tumors at the dosage range tested $(4-10 / \mathrm{mg} /$ day). These results support the safety and tolerability of Rv-PEM01 as a CAM therapy for pet dogs with cancer. Rv-PEM01 is a plant extract mixture derived from six kinds of herbs used in traditional Japanese medicine. Of these herbal components, $R$. verniciflua appears to be the main active herb. The branches and sap from $R$. verniciflua contain active compounds such as urushiol, fustin, querce 

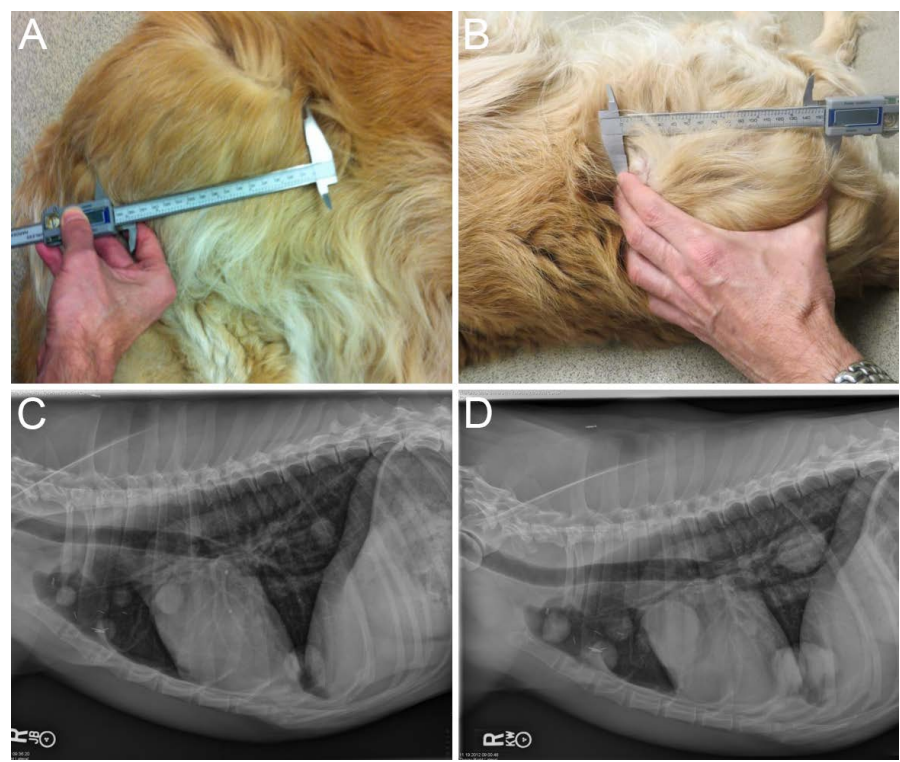

Figure 1. Assessment of tumor responses. Tumor responses were assessed by direct caliper measurements or by imaging at day 0 (panels (A) and (C)) and day 30 (panels (B) and (D)). Dog \#5 (subcutaneous hemangiosarcoma) had stable disease ((A) and (B)) and Dog \#1 (metastatic osteosarcoma) developed progressive disease after 30 days of treatment with Rv-PEM01.

tin, butein and sulfuretin; the antioxidant [15] [16], antitumorigenic [17] and cytotoxic [18] effects of these compounds have been reported. The antiproliferative activity of Rv-PEM01 has been demonstrated in human, mouse, and canine cell lines [11] [12]. Notably, D17, the one canine cell line that has been tested, is the most sensitive cell line tested to date [12].

The objective of this study was to demonstrate that Rv-PEM01 is safe and well tolerated in dogs with spontaneously occurring tumors. In dogs with a variety of different solid tumors, Rv-PEM01 induced no clinical signs attributable to the product, including no evidence of gastrointestinal toxicity (e.g. vomiting, diarrhea, anorexia) and no blood cell or biochemical abnormalities, other than transient mild elevations in BUN in two dogs that appeared to be due to non-renal causes. Given the lack of AEs associated with this product, Rv-PEM01 appears to be safe when administered as dosages up to $10 \mathrm{mg} / \mathrm{kg}$ orally once per day. Although an assessment of antitumor efficacy was not the primary objective of this study, tumor response assessments were made for all patients. Five of 12 dogs maintained stable disease over the course of the study. The clinical significance of stable disease over a 30 day period is difficult to determine and is likely variable with respect to the patient and tumor type. Three of the 5 dogs that maintained stable disease for 30 days had tumors (hemangiosarcoma, histiocytic sarcoma) that often progress rapidly; however, stable disease over this period of time can also be seen in untreateddogs. One of the remaining dogs that achieved stable disease had hepatocellular carcinoma, an often slowly progressive tumor in dogs; however, it is encouraging that this dog continued to receive Rv-PEM01 for another 10 months without evidence of toxicity, suggesting that longer-term, more chronic use of Rv-PEM01 is possible.

Rv-PEM01 was evaluated in dogs with spontaneous solid tumors in a dosage range compatible with tablet size of the product, patient size, and owner compliance. Although this dosage scheme met these criteria, and Rv-PEM01 was well tolerated at these dosages, the dosages used were significantly less than what would be needed to achieve blood concentrations of the active metabolites equivalent to their in vitro $\mathrm{IC}_{50}$ 's. In previous in vivo studies, single oral doses of $5.0 \mathrm{~g} / \mathrm{kg} \mathrm{Rv}$-PEM01 produced no evidence of acute toxicity in ddY mice, based on clinical observation, body weight change, and organ weights and chronic dosing at a dosage of $2.5 \mathrm{~g} / \mathrm{kg}$ daily for 28 days was similarly well tolerated [12]. Based on the excellent tolerability of Rv-PEM01 in tumor bearing dogs found in this study, the lack of apparent toxicity in mice when given Rv-PEM01 at much higher doses, and the concentrations of active compounds needed to produce antitumor activity in vitro, further studies of Rv-PEM01 at higher dosages in tumor bearing dogs are recommended. This will likely require reformulation to provide a convenient and palatable product for owners to administer to their pets. Future studies should also specifically address other potential benefits of Rv-PEM01 in canine cancer patients, including correlative as- 
sessments of immune function, quality of life, and owner satisfaction.

\section{Conclusion}

This study found Rv-PEM01 to be safe and well tolerated in pet dogs with spontaneously occurring solid tumors at the dosage range tested $(4-10 / \mathrm{mg} /$ day). Although no evidence of tumor regression was documented in any of the 12 dogs treated, this study was not designed as an efficacy trial, and a potential role for Rv-PEM01 as a complementary or alternative therapy for cancer treatment, or a role in chemoprevention, remains to be explored. Dosages of Rv-PEM01 evaluated here are significantly less than what is needed to produce antiproliferative effects in vitro [11] [12] suggesting that further studies are warranted in dogs at significantly higher dosage levels.

\section{Acknowledgements}

We are extremely grateful to Chairman and C.E.O. Masahito Hoashi, Kibun Foods Inc., for supporting the present work. We are indebted to Dr. Nobuo Yamaguchi, Ishikawa Natural Medicinal Products Research Center and Kanazawa Medical University for his perceptive suggestions. We are grateful to Drs. Kazunari Kadokura, Wataru Hiruma, Ms. Ayaka Miyata, Mrs. Tsuyoshi Tomita and Yoshihiro Sekino, Kibun Foods Inc., for the preparation of Rv-PEM01 and for their perceptive suggestions. The authors thank the Clinical Trials Office at The Ohio State University College of Veterinary Medicine for coordinating all aspects of this study. This project was also supported by the following grants: UL1TR001070 from the National Center for Advancing Translational Sciences and P30CA016058 from the National Cancer Institute to The Ohio State University.

\section{References}

[1] Heuberger, R. and Wakshlag, J. (2011) The Relationship of Feeding Patterns and Obesity in Dogs. Journal of Animal Physiology and Animal Nutrition, 95, 98-105. http://dx.doi.org/10.1111/j.1439-0396.2010.01024.x

[2] Barnes, P.M., Powell-Griner, E., McFann, K. and Nahin, R.L. (2004) Complementary and Alternative Medicine Use Among Adults: United States, 2002. Advance Data, 27, 1-19. http://dx.doi.org/10.1016/j.sigm.2004.07.003

[3] Richardson, M.A., Sanders, T., Palmer, J.L., Greisinger, A. and Singletary, S.E. (2000) Complementary/Alternative Medicine Use in a Comprehensive Cancer Center and the Implications for Oncology. Journal of Clinical Oncology, 18, 2505-2514.

[4] Navo, M.A., Phan, J., Vaughan, C., Palmer, J.L., Michaud, L., Jones, K.L., Bodurka, D.C., Basen-Engquist, K., Hortobagyi, G.N., Kavanagh, J.J. and Smith, J.A. (2004) An Assessment of the Utilization of Complementary and Alternative Medication in Women with Gynecologic or Breast Malignancies. Journal of Clinical Oncology, 22, 671677. http://dx.doi.org/10.1200/JCO.2004.04.162

[5] Frenkel, M., Abrams, D.I., Ladas, E.J., Deng, G., Hardy, M., Capodice, J.L., Winegardner, M.F., Gubili, J.K., Yeung, K.S., Kussmann, H. and Block, K.I. (2013) Integrating Dietary Supplements into Cancer Care. Integrative Cancer Therapy, 12, 369-384. http://dx.doi.org/10.1177/1534735412473642

[6] Raditic, D.M. and Bartges, J.W. (2014) Evidence-Based Integrative Medicine in Clinical Veterinary Oncology. Veterinary Clinics of North America Small Animal Practice, 44, 831-853. http://dx.doi.org/10.1016/j.cvsm.2014.06.002

[7] Lana, S.E., Kogan, L.R., Crump, K.A., Graham, J.T. and Robinson, N.G. (2006) The Use of Complementary and Alternative Therapies in Dogs and Cats with Cancer. Journal of the American Animal Hospital Association, 42, 361365. http://dx.doi.org/10.5326/0420361

[8] Ohno, T., Inoue, M. and Ogihara, Y. (2002) Suppressive Effect of Shichimotsu-koka-to (Kampo Medicine) on Pulmonary Metastasis of B16 Melanoma Cells. Biological and Pharmaceutical Bulletin, 25, 880-884. http://dx.doi.org/10.1248/bpb.25.880

[9] Childress, M.O., Burgess, R.C.F., Holland, C.H. and Gelb, H.R. (2011) Consequences of Intratumoral Injection of a Herbal Preparation Containing Blood Root (Sanguinaria canadensis) Extract in Two Dogs. Journal of the American Veterinary Medical Association, 239, 374-379. http://dx.doi.org/10.2460/javma.239.3.374

[10] Rayne, S. and Mazza, G. (2007) Biological Activities of Extracts from Sumac (Rhus spp): A Review. Plant Foods for Human Nutrition, 62, 165-175. http://dx.doi.org/10.1007/s11130-007-0058-4

[11] Hiruma, W., Suruga, K., Kadokura, K., Tomita, T., Sekino, Y., Komatsu, Y., Kimura, M. and Ono, N. (2013) The Antitumor Effects of a Plant Extract Mixture. Yakugaku Zasshi, 133, 487-491. 
http://dx.doi.org/10.1248/yakushi.12-00278-1

[12] Hiruma, W., Suruga, K., Kadokura, K., Tomita, T., Miyata, A., Sekino, Y., Kimura, M., Yamaguchi, N., Komatsu, Y., Buffington, C.A.T. and Ono, N. (2015) Antitumor Effects and Acute Oral Toxicity Studies of a Plant Extract Mixture Containing Rhus verniciflua and Some Other Herbs. Open Journal of Immunonology, 5, 39-49. http://dx.doi.org/10.4236/oji.2015.51005

[13] Veterinary Cooperative Oncology Group (2011) Common Terminology Criteria for Adverse Events (VCOG-CTCAE) Following Chemotherapy or Biological Antineoplastic Therapy in Dogs and Cats v1.1. Veterinary and Comparative Oncology. (Epub Ahead of Print)

[14] Nguyen, S.M., Thamm, D.H., Vail, D.M. and London, C.A. (2015) Response Evaluation Criteria for Solid Tumours in Dogs (v1.0): A Veterinary Cooperative Oncology Group (VCOG) Consensus Document. Veterinary and Comparative Oncology, 13, 176-183. http://dx.doi.org/10.1111/vco.12032

[15] Lee, J.C., Kim, J., Lim, K.T., Yang, M.S. and Jang, Y.S. (2001) Ethanol Eluted Extract of Rhus verniciflua Stokes Showed Both Antioxidant and Cytotoxic Effects on Mouse Thymocytes Depending on the Dose and Time of the Treatment. Journal of Biochemistry and Molecular Biology, 34, 250-258.

[16] Lee, J.C., Lim, K.T. and Jang, Y.S. (2002) Identification of Rhus verniciflua Stokes Compounds That Exhibit Free Radical Scavenging and Anti-Apoptotic Properties. Biochemica et Biophysica Acta, 1570, 181-191. http://dx.doi.org/10.1016/S0304-4165(02)00196-4

[17] Lee, J.C., Lee, K.Y., Kim, J., Na, C.S., Jung, N.C., Chung, G.H. and Jang, Y.S. (2004) Extract From Rhus verniciflua Stokes is Capable of Inhibiting the Growth of Human Lymphoma Cells. Food and Chemical Toxicology, 42, 13831388. http://dx.doi.org/10.1016/j.fct.2004.03.012

[18] Kitts, D.D. and Lim, K.T. (2001) Antitumorigenic and Cytotoxic Properties of an Ethanol Extract Derived from Rhus verniciflua Stokes (RVS). Journal of Toxicology and Environmental Health A, 64, 357-371.

\section{Submit or recommend next manuscript to SCIRP and we will provide best service for you:}

Accepting pre-submission inquiries through Email, Facebook, Linkedin, Twitter, etc A wide selection of journals (inclusive of 9 subjects, more than 200 journals)

Providing a 24-hour high-quality service

User-friendly online submission system

Fair and swift peer-review system

Efficient typesetting and proofreading procedure

Display of the result of downloads and visits, as well as the number of cited articles

Maximum dissemination of your research work

Submit your manuscript at: http://papersubmission.scirp.org/ 